\title{
Nota sôbre o gênero Mononchus de nematódeos predadores
}

\author{
LUIZ GONZAGA E. LORDELLO
}

Escola Superior de Agricultura "Luiz de Queiroz" Universidade de S. Paulo - Piracicaba

INDICE

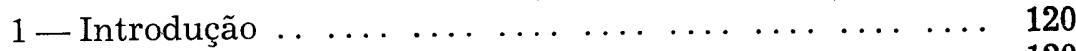

2 - Mononchus jairi n. sp. . ................... 120

$\begin{array}{llllllllllll}3 \text { - Summary } & . & \ldots & \ldots & \ldots & \ldots & \ldots & \ldots & \ldots & \ldots & \ldots & \ldots\end{array}$

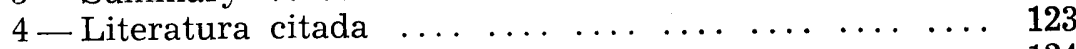

$\begin{array}{llllllllll}5 & - \text { Nota adicional } & \ldots & \ldots & \ldots & \ldots & \ldots & \ldots & \ldots & \ldots\end{array}$ 


\section{1 - INTRODUÇÃO}

A fauna de nematódeos do gênero Mononchus Bastian, 1865, do Estado de S. Paulo, graças principalmente aos trabalhos de CARVALHO (1951, 1953, 1955, 1956, 1956a), vem sendo paulatinamente conhecida. Os estudos dêste autor trouxeram ao conhecimento da ciência quatro interessantes e boas espé-. cies: M. ibitiensis Carvalho, 1951; M. risoceiae Carvalho, 1955; M. soutoi Carvalho, 1956; e M. coronatus Carvalho, 1956.

Em 1953, encontramos, em amostras de solo coletadas em Piracicaba, a espécie $M$. piracicabae Lordello, 1953. Recentemente, MEYL (1957) assinalou a ocorrência de $M$. subsimilis Cobb, 1917, em Santos. As espécies mencionadas, mais a que adeante descrevemos como nova para a ciência, perfazem o total de apenas 7 formas conhecidas para o Estado de S. Paulo, permitindo-nos aguardar por interessantes e ainda numerosas adições.

Ao estudar a espécie $M$. piracicabae, tivemos em mãos uma rica população, fazendo-nos inicialmente pensar que se tratava do único nematódeo presente nas amostras de solo manipuladas. Entretanto, foram também obtidos indivíduos pertencentes a vários gêneros de nematódeos parasitos de plantas, tais como Meloidogyne, Pratylenchus, Criconemoides, etc. Acontece que no local onde foram coletadas as amosiras, foi a seguir instalada cultura de algodoeiro sem que se tivesse notado qualquer ação sôbre as plantas dos nematódeos parasitos referidos. Interpretamos o fato como decorrente da ação pr adadora da numerosa população de $M$. piracicabae presente na gleba, constituindo mais uma demonstração do papel dêstes animais na manutenção do equilíbrio biológico dentro da fauna do solo (STEINER \& HEINLY, 1922).

Damos a seguir, a descrição de Mononchus jairi n. sp. recentemente obtido de amostra de solo procedente de Martinópolis, E. S. Paulo.

\section{2 - MONONCHUS JAIRI N. SP.}

Dimensões (em micros) : comp. total: 788,0-924,0; largura: $32,1-33,7$; faringe: $30,6 \times 23,0-27,0$; esôfago: $223,4-240,0$; distância da frente da cabeça à vulva: 578,4-679,3; cauda: 53,5-68,8; diâmetro do corpo na altura do ânus: $21,4-23,0$; distância vulvaânus: $145,4-176,0 ; \quad a=24,4-27,4 ; \quad b=3,5-3,8 ; \quad c=12,2-15,6$;

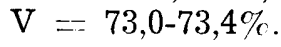




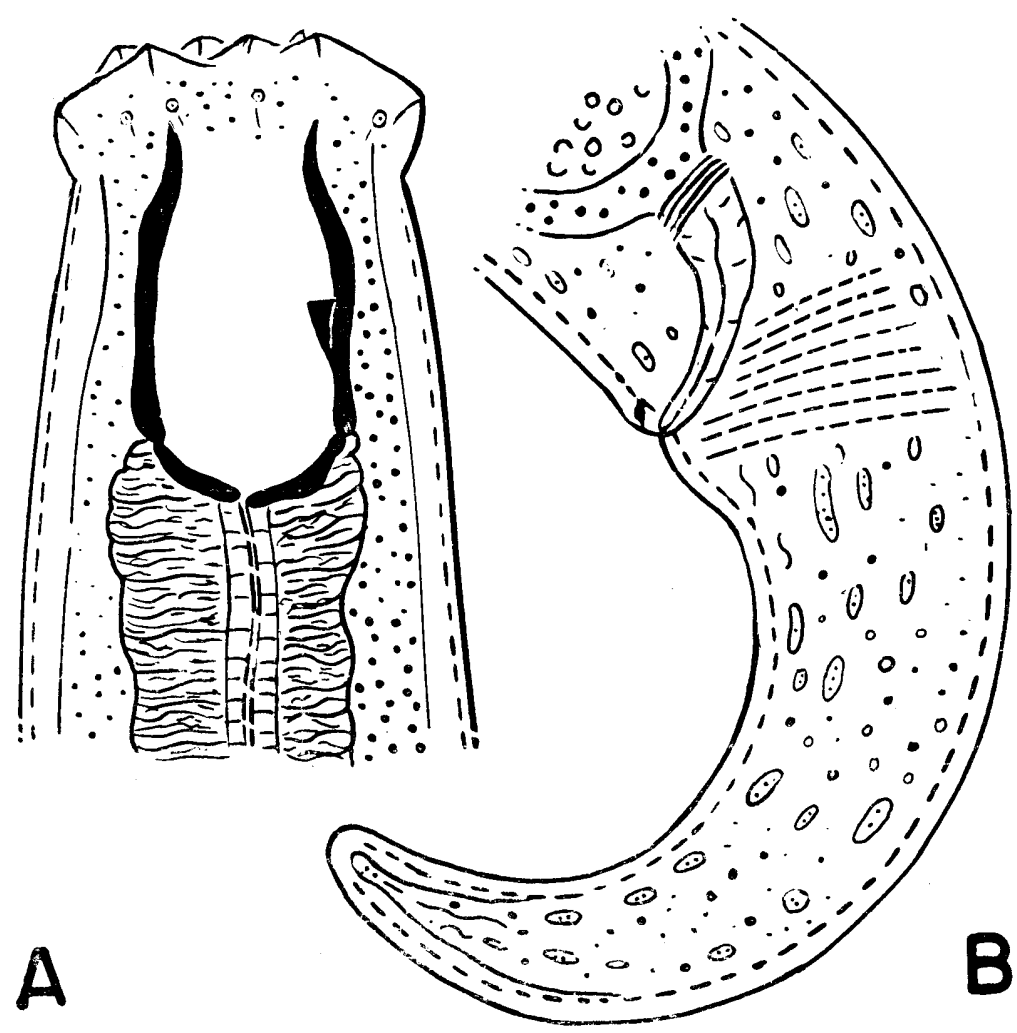

Mononchus jairi n. sp. A - Região anterior; B-cauda

Corpo afinando-se levemente para a extremidade anterior e mais intensamente para a posterior, terminando em cauda afilada é convexa no lado ventral.

Cutícula lisa, campos laterais obscuros. Região labial separada do corpo por uma depressão não profunda, exibindo as proeminentes papilas usuais. Amphids não divisados.

Faringe prcvida de um único dente dorsal, localizado em seu nível médio. Os extremos anteriores da parede faringeana. abrem-se para fora, ao mesmo tempo perdendo espessura.

O esôfago expande-se na região de sua junção com a base da faringe. Càrdia grosseiramente cônico e curto. Células intestinais baixas, poligonais, tomadas de grânulos escuros. Cêrca de 7 células perfazem uma circunferência intestinal. 
Ânus localizado em uma elevação, provido de poderosa musculatura dilatadora. ( *).

$\mathrm{Na}$ base do reto de um dos indivíduos estudados, pôde-se perceber a existência de três ou quatro anéis musculares, parecendo um esfíncter, o que constitui mais um detalhe anatûmico relacionado ao modus vivendi da espécie.

Vagina oblíqua em relação à linha ventral, pois se apresenta inclinada para a frente, com comprimento valendo cêrca de um têrço da largura do corpo. Ovário único (espécie prodèlfica), reflexo. Tôdas as fêmeas examinadas mostravam útero vazio. No ovário, o maior oócito, aparentemente prestes a ganhar o útero, mediu cêrca de $61,2 \times 27,5$ micros. $O$ ponto onde o ovário apresenta a reflexão dista ao redor de 157 micros da vulva. Tal distância representa $17 \%$ do comprimento total da fêmea.

Cauda afilada, arqueada ventralmente, com ponta rombuda. Spinneret ausente.

Diagnose - $M$. jairi n. sp. assemelha-se muito à espécie M. monhystera Cobb, 1916, descrita da Bahia, com a yual foi inicialmente identificado. Entretanto, difere: a) por apresentar região labial expandida, separada do resto do corpo pnr uma depressão larga e pouco profunda; b) pela diferente o1ganização da faringe, cujas paredes, em seu extremo distal, abrem-se para fora, ao mesmo tempo que perdem espessura; e, c) pelas dimensões (comprimento 788,0-924,0: 1.100,0 micros; $\mathrm{V}=73,0-73,4 \%: \mathrm{V}=78,0 \%) \quad(\mathrm{COBB}, 1917)$.

Localidade típica: Martinópolis, Estado de S. Paulo, de amostra de solo coligida ao redor de raízes de cafeeiro (Coffea arabica L.) desfiguradas por Meloidogyne exigua Goeldi, 1887.

Hábitos: M. jairi n. sp. alimenta-se de outros nematódeos, tendo sido fixado um exemplar no momento em que atacava uma larva de uma espécie não identificada, pertencente à família Cephalobidae Chitwood \& Chitwood, 1934.

Machos desconhecidos; sòmente fêmeas e larvas foram obtidas.

O nome específico foi dado em homenagem ao Dr. JAIR C. DE CARVALHO, nematólogo do Instituto Biológico de S. Paulo.

(*) Aliás, em Mononchus, há necessidade de músculos anais bem desenvolvidos, devido à natureza física das fezes que, por certo, com frequência incluem restos das vítimas, que não foram digeridos. 


\section{3 - SUMMARY}

Seven species of the nematode genus Mononchus Bastian, 1865, were found in the State of São Paulo, Brazil. Such are: M. subsimilis Cobb, 1917; M. ibitiensis Carvalho, 1951; M. piracicabae Lordello, 1953; M. risoceiae Carvalho, 1955; M. soutoi Carvalho, 1956; $M$. coronatus Carvalho, 1956; and $M$. jairi n. sp. Outside the State, the following species have been found: M. papillatus (Bastian, 1865) Cobb, 1916; M. monhystera Cobb, 1917; M. muscorum (Dujardin, 1845) Cobb, 1916; M. gymnolaimus (Cobb, 1893) Cobb, 1916; M. consimilis Cobb, 1917; M. trichurus Cobb, 1917; M. reversus Cobb, 1917; and M. dentatus Cobb, 1917 (LORDELLO, 1953).

This field of investigation has scarcely been touched and additional collections will doubtless add new forms to the number of species known as yet.

M. jairi n. sp. most closely resembling species is $M$. monhystera Cobb, 1917, from which it differs in having: a) labial region more expanded, set off from neck by a broad shallow depression; b) anterior portion of the pharynx wall rather thinner and directed outward; and, c) smaller dimensions (788.0924.0: $1,100.0$ micros).

\section{4 - LITERATURA CITADA}

CARVALHO, J. C., 1951 - Uma nova espécie de Mononchus (Nematoda, Mononchidae). Bragantia 11: 51-54.

CARVALHO, J. C., 1953 - Mononchus, um predador voraz. Rev. Inst. Adolfo Lutz 13: 75-82.

CARVALHO, J. C., 1955 - Mononchus risoceiae, nova espécie (Nematoda, Mononchidae). Rev. Inst. Adolfo Lutz 15: 129134.

CARVALHO, J. C., 1956 - Mononchus soutoi sp. n. (Nematoda, Mononchidae). Rev. Brasil. Biol. 16: 133-134.

CARVALHO, J. C., 1956a - Mononchus coronatus n. sp. (Nematoda, Mononchidae). Rev. Inst. Adolfo Lutz 16: 148-150.

COBB, N. A., 1917 - The mononchs (Mononchus Bastian, 1866), a genus of free-living predatory nematodes. Em "Contributions to a Science of Nematology", VI, pp. 129184.

LORDELLO, L. G. E., 1953 - Contribuição ao conhecimento dos nematódeos do solo de algume's regiões do Estado de São Paulo. Escola Sup. de Agric. "Luiz de Queiroz", tese, 75 pp., 5 ests.

MEYL, A. H., 195, - Beitraege zur freilebenden Nematodenfauna Brasiliens. II. Weitere neue oder wenig bekannte Nematodenarten. Kieler Meeresf. 13: 125-133. 
STEINER, G. \& H. HEINLY, 1922 - The possibility of control of Heterodera radicicola and other plant - injurious nemas by means of predatory nemas, especially by MOnonchus papillatus Bastian. Jour. Wash. Acad. Sci. 12: 367-386.

\section{5 - NOTA ADICIONAL}

Êste artigo já se achava entregue à publicação, quando recebemos o trabalho de I. ANDRASSY (1958): Ueber das System der Mononchiden, aparecido no tomo 50 (Series nova IX) dos Annales Historico - Naturales Musei Nationalis Hungarici, páginas 151-171, no qual são elevados à categoria de gêneros os cinco velhos subgêneros erigidos por COBB em 1916 e 1917 (Prionchulus, Anatonchus, Iotonchus, Mylonchulus e Sporonchulus), sendo também creadas cinco novas entidades genéricas: Cobbonchus, Miconchus, Judonchulus, Granonchulus e Brachonchulus. Os nematódeos até então referidos para o gênero Mononchus Bastian, 1865, ficaram, pois distribuidos por 11 agrupamentos diferentes.

As espécies mencionadas neste artigo, para São Paulo, passaram a ser denominadas: Sporonchulus ibitiensis (Carvalho, 1951) Andrássy, 1958; Iotonchus risoceiae (Carvalho, 1955) Andrássy, 1958; Miconchus soutoi (Carvalho, 1956) Andrássy, 1958; Sporonchulus coronatus (Carvalho, 1956) Andrássy, 1958; Mylonchulus subsimilis (Cobb, 1917) Andrássy, 1958; e, Iotonchus piracicabae (Lordello, 1953) Andrássy, 1958.

Das demais formas que ocorrem no Brasil, algumas passaram a constituir combinações novas: Prionchulus muscorum (Dujardin, 1845) Andrássy, 1958; Iotonchus gymnolonimus (Cobb, 1893) Andrássy, 1958; Iotonchus consimilis (Cobb 1917) Andrássy, 1958; Iotonchus trichurus (Cobb, 1917) Andrássy, 1958; Mylonchulus reversus (Cobb, 1917) Andrássy, 1958; e Sporonchulus dentatus (Cobb, 1917) Andrássy, 1958.

NOTA SINONIMICA - Em 1953, CARVALHO descreveu um nematódeo do grupo em estudo, sem contudo identificá-lo, tendo-o referido como Mononchus (Iotonchus) sp. Logo depois, CARVALHO (1955) pôde verificar que se tratava de uma espécie nova, que então tornou a descrever como Mononchus risoceiae n. sp. Entretanto, ANDRÁSSY, talvez por ignorar o trabalho de CARVALHO de 1955, erigiu a nova espécie Iotonchus carvalhoi para conter o nematódeo descrito em 1953 como Mononchus (Iotonchus) sp.

Do exposto, conclui-se que I. carvalhoi Andrássy, 1958, c um sinônimo de I. risoceiae (Carvalho, 1955) Andrássy, 1958. 